\title{
FEATURES OF ARTERIAL HYPERTENSION COMBINED WITH OBESITY ACCORDING TO NON-ALCOHOLIC FATTY LIVER DISEASE (STEATOSIS AND STEATOHEPATITIS)
}

\author{
Olesia Bochar \\ Ph.D., Associate Professor, Danylo Halytsky Lviv National Medical University, Ukraine \\ e-mail: olesjabarduw@ukr.net,orcid.org/0000-0001-5000-9415
}

Volodymyr Bochar

Ph.D., Associate Professor, Danylo Halytsky Lviv National Medical University, Ukraine e-mail: bovotar@ukr.net,orcid.org/0000-0002-5100-8657

\section{Summary}

This research was aimed to estimate the course of hypertension on the background of obesity and nonalcoholic fatty liver disease according to its stages (steatosis and steatohepatitis). Ninety patients were evaluated for anthropometric, general-clinical, laboratory, instrumental and immune-enzymatic research methods. With USG, the most characteristic features of fatty liver infiltration and the criteria for the distinction of steatosis from steatohepatitis were revealed, and on the basis of them 2 groups were formed.

Thus, the progression of nonalcoholic fatty liver disease to the stage of steatohepatitis was accompanied by a more pronounced increase in blood pressure larger in comparison with steatosis of mass index of myocardium and anterior-posterior size of the left atrium, indicating the progression of structural myocardial disorders. Therefore, the presence of non-alcoholic steatohepatitis in patients with hypertension can be regarded as unfavorable prognostic criteria for the development of heart failure. In the presence of steatohepatitis, more marked changes in lipidograms were noticed for Low-Density Lipoprotein and Triglyceride values and a violation of the functional state of the liver with a cytolytic syndrome on the activity of AST and ALT and the total bilirubin, which may contribute to the progression of liver damage. obesity.

Keywords: arterial hypertension, nonalcoholic fatty liver disease, metabolic syndrome,

\section{DOI: https://doi.org/10.23856/4627}

\section{Introduction}

Studies of recent years show that almost always hypertension is accompanied by a number of metabolic disorders (Katsimardou, 2020).

The generally accepted cause of MS (metabolic syndrome) is genetic predisposition to it (Clearfield, 2014). In its development, two stages are distinguished. The first one is manifested by insulin resistance and hypodynamia (mainly in elderly people), and the second is a violation of the function of insulin-producing cells. In today's world, metabolic syndrome on the background of obesity often occurs in children and young people (Bochar, 2021: 313).

Therefore, the central place in the pathogenesis of MS is insulin resistance, in which there is a violation of the action of insulin on the postreceptor level in target tissues - the liver, skeletal muscle and adipose tissue (Targher, 2016). 
One of the features of the MS is the increase in blood supply to the free fatty acids, which leads to the development of atherosclerosis and changes in the liver in the form of fatty liver (Festuccia, 2017).

NAFLD (nonalcoholic fatty liver disease) is a disease characterized by accumulation of fat in the liver (not less than 5\% of hepatocytes) and an increase in body weight by 5-10\% (Fargio, 2014). This is the most common pathology among all chronic liver diseases. It often leads to deterioration in the patient's quality of life, disability and death as a result of the progression of steatosis, non-alcoholic steatohepatitis (NASH), fibrosis, cirrhosis, hepatic failure and hepatocellular carcinoma (Anstee, 2019; Schwabe, 2020).

The aim is to estimate the course of hypertension on the background of obesity and NAFLD according to the stages of NAFLD (steatosis and steatohepatitis).

\section{Materials and methods}

Ninety patients diagnosed with arterial hypertension, obesity and NAFLD were examined. All patients underwent clinical, laboratory and instrumental examinations on combined pathology. All patients were evaluated for anthropometric, general-clinical, laboratory (lipid blood spectrum), instrumental (electrocardiography, echocardiography, ultrasonography (USG)) and immune-enzymatic research methods (adiponectin). The measurements of patients height and weight were done and the body mass index in accordance with generally accepted formulas was also calculated. The level of office blood pressure was measured in the morning in a sitting position on the same arm at an interval of $2 \mathrm{~min}$. three times and calculated the average of three measurements. The heart rate was determined after the second measurement.

With USG, the most characteristic features of fatty liver infiltration and the criteria for the distinction of steatosis from steatohepatitis were revealed, and on the basis of them 2 groups were formed (the first group - patients with steatosis, the second - with steatohepatitis). The criteria for steatosis according to USG data were: increased liver size; homogeneous, diffuse increase in its echogenicity (the so-called «white liver»), the effect of distal shading disturbance of visualization of the vascular pattern (Zhou, 2017). The criteria for steatohepatitis were: hyperhogenicity of tissues due to diffuse fatty liver infiltration, inhomogeneous sealing of its structure, first signs of portal hypertension (increase in the diameter of the portal vein).

Diagnosis of hypertension was established according to the standards of diagnosis and treatment in accordance with the recommendations of the Ukrainian Association of Cardiologists, the European Society for Arterial Hypertension and the European Society of Cardiologists (ESH/ ESC, 2018). When choosing a survey plan and treatment tactics, approved by Orders of the Ministry of Health of Ukraine and recommendations of the American Association of Gastroenterology (AGA), American Association for the Study of Liver Diseases (AASULD), were used.

The obtained results were statistically processed using Student's criterion, Pearson correlation analysis using the Microsoft Excel computer program.

\section{Results and discussion}

Among the examined men in the group with combined pathology (hypertension with obesity and NAFLD) there were $35(38.9 \%)$, women - $55(61.1 \%)$, the average age was $(56.59 \pm 1.11)$ years. A significant prevalence of female patients is revealed, which indicates a higher prevalence of hypertension among women than among men, which is consistent with those of other authors (O'Neil, 2018). 
In order to assess the course of hypertension in the context of obesity and NAFLD, the patients were divided into groups based on clinical and sonographic criteria in the stages of NAFLD (steatosis and steatohepatitis).

Ultrasonographic increase in liver size was found in $48(96.0 \%)$ patients with steatohepatitis and in $27(67.5 \%)$ patients with steatosis $(\mathrm{p}<0.05)$ (Table 1$)$.

Table 1

Results of liver and gallbladder ultrasonography in the groups of patients with steatosis and steatohepatitis

\begin{tabular}{|l|c|c|c|c|}
\hline \multirow{2}{*}{ Ultrasonographic criteria } & \multicolumn{2}{c|}{ Steatosis (n=40) } & \multicolumn{2}{c|}{ Steatohepatitis (n=50) } \\
\cline { 2 - 5 } & Abs. & $\mathbf{\%}$ & Abs. & \% \\
\hline Increased liver size & 27 & 67,5 & 48 & $96,0^{*}$ \\
\hline Hyperechogenicity of the liver tissue & 25 & 62,5 & 48 & $96,0^{*}$ \\
\hline Gallbladder neck bending & 12 & 30,0 & 40 & $80,0 *$ \\
\hline
\end{tabular}

Note: ${ }^{*}-\mathrm{p}<0,05$ compared with a group of steatoses

Hyperergenic liver parenchyma was observed in $48(96.0 \%)$ patients with steatohepatitis and in $25(62.5 \%)$ patients with steatosis $(\mathrm{p}<0.05)$. The heterogeneity of the structure of the liver is diagnosed only in $46(92.0 \%)$ patients with steatohepatitis. The hypertrophy of the neck of the gallbladder occurred in $12(30.0 \%)$ patients with steatosis and $40(80.0 \%)$ with steatohepatitis $(p<0.05)$.

Dimensions of the right lobe of the liver in patients with steatohepatitis were $(15,18 \pm 0.11)$ $\mathrm{cm}$ and significantly differed from those in patients with steatosis by $14,8 \%(\mathrm{p}<0,05)$. A significant increase of almost $2 \mathrm{~cm}$ in the size of the right lobe of the liver in patients with steatohepatitis was noted. In the patients with signs of steatosis, the left lobe of the liver was small in size $(7.66 \pm 0.09) \mathrm{cm}$ and was lower in $1.69 \%$ of patients with steatohepatitis (Table 2).

Table 2

\section{Results of liver ultrasonography in the groups of patients with steatosis and steatohepatitis $(M \pm m)$}

\begin{tabular}{|l|c|c|}
\hline \multicolumn{1}{|c|}{ Ultrasonographic criteria } & Steatosis $(\mathbf{n}=\mathbf{4 0})$ & Steatohepatitis $(\mathbf{n}=\mathbf{5 0})$ \\
\hline Size of the liver right lobe, $\mathrm{cm}$ & $13,22 \pm 0,20$ & $15,18 \pm 0,11^{*}$ \\
\hline Size of the liver left lobe, $\mathrm{cm}$ & $7,66 \pm 0,09$ & $7,79 \pm 0,09$ \\
\hline Diameter of the portal vein, $\mathrm{mm}$ & $11,36 \pm 0,18$ & $13,12 \pm 0,16^{*}$ \\
\hline
\end{tabular}

Note: ${ }^{*}-\mathrm{p}<0,05$ compared with a group of steatoses

The VP diameter in patients with steatohepatitis on average was $(13.12 \pm 0.16) \mathrm{mm}$ and was significantly higher than the diameter of VP in the group of patients with steatosis by $15.5 \%$ $(\mathrm{p}<0.05)$. Thus, the presence of steatohepatitis was confirmed by a possible increase in the size of the liver, its hyperhogicity with a heterogeneous seal of its echostructure and by the expansion of the diameter of the VP.

The average age of patients diagnosed with steatosis was $(57.40 \pm 1.58)$ years, and with steatohepatitis was $(55.62 \pm 1.54)$ years. The biggest part of the examined patients consisted of patients aged 45-59 years, both in the group with steatosis and with steatohepatitis.

Both in the group of steatoses and in the steatohepatitis group, in all patients, arterial hypertension of the stage II and the 2 nd degree established. In the risk stratification of arterial 
hypertension to estimate the prognosis, medium risk was observed in $25(62.5 \%)$ patients, high in $15(37.5 \%)$ patients in the group of patients with steatosis and medium - in $23(46.0 \%)$, high - in $27(54.0 \%)$ persons in the group of patients with steatohepatitis accordingly.

The average level of SBP (systolic blood pressure) in patients with steatohepatitis was equal $(168,50 \pm 2,11) \mathrm{mm} \mathrm{Hg}$. Art. and, accordingly, was higher by $3.80 \%$ than in the group of patients with steatosis $((162.33 \pm 1.17) \mathrm{mm} \mathrm{Hg}),(\mathrm{p}<0.05)$.

The average level of DBP (diastolic blood pressure) in the group of patients with steatohepatitis was $(108,40 \pm 0,70) \mathrm{mm} \mathrm{Hg}$. Art. and exceeded similar indices in patients with steatosis $((101.42 \pm 0.85) \mathrm{mm} \mathrm{Hg})$ at $6.88 \%(\mathrm{p}<0.05)$. The heart rate in patients with steatosis was $(81.53 \pm 0.46)$ for $1 \mathrm{~min}$, and in patients with steatohepatitis $-(85.92 \pm 0.67)$ for $1 \mathrm{~min}$ and was higher by $5.38 \%$ compared with steatosis patients.

As patients with steatosis, as well as patients with steatohepatitis complained of periodic headache (mainly in the occipital and frontal areas) in 90.0\% and $94.0 \%$ respectively. Thirty-three $(82.5 \%)$ patients with steatosis and $50(100.0 \%)$ patients with steatohepatitis also had a deterioration of their health and rapid fatigue. Drowsiness and noises in the ears were diagnosed in $62(68.9 \%)$ of patients, flashing of the «flies» before the eyes in $28(31.1 \%)$, sleep disturbances in $59(65.5 \%)$, periodic pain in the heart or in the sternum, precisely at the time of an increase in blood pressure - in $44.4 \%$ of patients.

Clinically, steatosis was asymptomatic in $35(87.5 \%)$ patients, feeling of heaviness and dyspeptic manifestations were observed in $5(12.5 \%)$ patients, and in case of steatohepatitis, asymptomatic course was diagnosed in $24(48.0 \%)$ patients accordingly and pain sensations in the right hypochondrium in $26(52.0 \%)$.

All patients were treated with echocardiography. In the examined patients, changes in some of the indicators, including the violation of local contractility of left atrium, were detected. For the results of echocardiography in patients with steatohepatitis, the size of the left atrium and the mass index of myocardium were significantly lower by $8.0 \%$ and $19.8 \%$, respectively, compared with the group of patients with steatosis $(\mathrm{p}<0.05)$ (Table 3$)$.

Table 3

\section{Echocardiography results in patients with arterial hypertension and obesity depending on the stage of non-alcoholic fatty liver disease}

\begin{tabular}{|l|c|c|}
\hline \multicolumn{1}{|c|}{ Indicators (norms) } & $\begin{array}{c}\text { Steatosis } \\
(\mathbf{n = 4 0 )}\end{array}$ & $\begin{array}{c}\text { Steatohepatitis } \\
(\mathbf{n = 5 0 )}\end{array}$ \\
\hline Size of the right ventricle, $(0,9-2,6 \mathrm{~cm})$ & $2,37 \pm 0,04$ & $2,36 \pm 0,04$ \\
\hline The thickness of the interventricular septum, $(0,6-1,1 \mathrm{~cm})$ & $1,05 \pm 0,03$ & $1,07 \pm 0,03$ \\
\hline Size of the left ventricle, $(3,5-5,7 \mathrm{~cm})$ & $4,76 \pm 0,08$ & $4,88 \pm 0,14$ \\
\hline The thickness of the left ventricle back wall, $(0,6-1,1 \mathrm{~cm})$ & $1,10 \pm 0,02$ & $1,08 \pm 0,04$ \\
\hline Front and back size of the left atrium, $(1,9-4,0 \mathrm{~cm})$ & $4,12 \pm 0,03$ & $4,45 \pm 0,07^{*}$ \\
\hline Size of the ascending aorta, $(2,0-3,7 \mathrm{~cm})$ & $3,10 \pm 0,04$ & $3,16 \pm 0,07$ \\
\hline Release faction (more than 55\%) & $56,92 \pm 0,74$ & $56,62 \pm 0,66$ \\
\hline Mass of myocardium (male $115-150 \mathrm{~g}$, female $95-120 \mathrm{~g})$ & $183,78 \pm 8,77$ & $188,51 \pm 14,71$ \\
\hline $\begin{array}{l}\text { Mass index of myocardium }\left(\text { male } 71-94 \mathrm{~g} / \mathrm{m}^{2}, \text { female }\right. \\
\left.\text { 71-89 g/m }{ }^{2}\right)\end{array}$ & $91,07 \pm 4,44$ & $109,07 \pm 6,34 *$ \\
\hline Relative thickness of the myocardium & $0,44 \pm 0,01$ & $0,47 \pm 0,01$ \\
\hline
\end{tabular}

Note: ${ }^{*}-\mathrm{p}<0,05$ compared with a group of steatoses 
In our opinion, steatohepatitis has a more pronounced adverse effect than steatosis, on the remodeling of the structural state of the myocardium in patients with hypertension. It correlates with the results of other authors (VanWagner, 2017; Vakalyuk, 2016).

The mean total cholesterol level in patients with steatosis was $(5.85 \pm 0.08) \mathrm{mmol} / \mathrm{L}$ and significantly differed from that in patients with steatohepatitis, where it was equal to $(6.24 \pm 0.18)$ $\mathrm{mmol} / \mathrm{L}$ and was higher by $6.7 \%$ compared with patients with steatosis $(\mathrm{p}<0,05)$. The increase in total cholesterol parameters to some extent depended on the development of fatty liver infiltration, namely, the formation of NASH, which, in turn, contributed to a violation of cholesterol synthesis in hepatocytes (Table 4).

Table 4

Indicators of the lipid spectrum of blood in patients with arterial hypertension on the background of obesity and NAFLD depending on its stage

\begin{tabular}{|l|c|c|}
\hline \multicolumn{1}{|c|}{ Indicators } & Steatosis $(\mathbf{n = 4 0 )}$ & Steatohepatitis $(\mathbf{n = 5 0})$ \\
\hline Total cholesterol, Mmol/L & $5,85 \pm 0,08$ & $6,24 \pm 0,18^{*}$ \\
\hline Triglycerides, Mmol/L & $2,01 \pm 0,14$ & $2,26 \pm 0,11$ \\
\hline Low density lipoprotein, Mmol/L & $3,27 \pm 0,12$ & $3,99 \pm 0,18^{*}$ \\
\hline High density lipoprotein, Mmol/L & $1,12 \pm 0,05$ & $1,16 \pm 0,06$ \\
\hline
\end{tabular}

Note: ${ }^{*}-\mathrm{p}<0,05$ compared with a group of steatoses

The average level of LDL (Low-Density Lipoprotein) in the steatohepatitis subjects was $(3.99 \pm 0.13) \mathrm{mmol} / \mathrm{L}$ and was significantly higher at $22.0 \%$ compared with those examined for steatosis $(\mathrm{p}<0.05)$. The TG (Triglyceride) level was $(2.26 \pm 0.11) \mathrm{mmol} / \mathrm{L}$ in patients with steatohepatitis and was higher by $12.4 \%$ than patients with steatosis. There was no significant difference in HDL (Hight-Density Lipoprotein) and TG levels among patients in both groups.

A more pronounced dyslipidemia was observed in patients with steatohepatitis in terms of TG and LDL, which probably contributed to the development of inflammatory process in the presence of NAFLD and the formation of NASH (Diehl, 2017).

In determining the activity of liver transaminases in the group of patients with steatohepatitis, the mean value of ALT was $(0.71 \pm 0.09) \mathrm{mmol} /(\mathrm{h} \times \mathrm{l})$ and exceeded the similar index in 1.22 times with steatosis $(\mathrm{p}<0.05)$. The activity of AST in the patients with steatohepatitis was $(0,55 \pm 0,03) \mathrm{mmol} /(\mathrm{h} \times \mathrm{l})$ and was higher in 1,1 times than in the group of patients with steatosis $(\mathrm{p}<0,05)$, (Table. 5).

Table 5

Levels of hepatic transaminases and bilirubin in patients with arterial hypertension on the background of obesity and NAFLD depending on its stage

\begin{tabular}{|l|c|c|c|}
\hline \multicolumn{1}{|c|}{ Indicators } & $\begin{array}{c}\text { Control group } \\
(\mathbf{n = 2 0 )}\end{array}$ & $\begin{array}{c}\text { Steatosis } \\
(\mathbf{n = 4 0 )}\end{array}$ & $\begin{array}{c}\text { Steatohepatitis } \\
(\mathbf{n = 5 0 )}\end{array}$ \\
\hline ALT, Mmol/L $/(\mathrm{h} \times 1)$ & $0,48 \pm 0,01$ & $0,58 \pm 0,03 \bullet$ & $0,71 \pm 0,09^{*}$ \\
\hline AST, Mmol/L $/(\mathrm{h} \times 1)$ & $0,38 \pm 0,02$ & $0,50 \pm 0,02$ & $0,55 \pm 0,03 *$ \\
\hline Total bilirubin, Mcmol/L & $9,45 \pm 0,25$ & $11,41 \pm 0,42 \bullet$ & $16,08 \pm 0,89 *$ \\
\hline
\end{tabular}

The activity of AST and ALT both in healthy individuals and in steatosis patients did not exceed the reference values. 
The level of total bilirubin in patients with steatohepatitis was $(16.08 \pm 0.89) \mathrm{mcmol} / \mathrm{L}$ and significantly differed from that in patients with steatosis in 1.4 times and in comparison, with the control group in 1.7 times $(\mathrm{p}<0,05)$.

\section{Conclusions}

Thus, the progression of NAFLD to the stage of steatohepatitis was accompanied by a more pronounced increase in SBP and DBP larger in comparison with steatosis of mass index of myocardium and anterior-posterior size of the left atrium, indicating the progression of structural myocardial disorders. Therefore, in our opinion, the presence of NASH in patients with hypertension can be regarded as unfavorable prognostic criteria for the development of heart failure.

In the presence of steatohepatitis, more marked changes in lipidograms were noticed for Low-Density Lipoprotein and Triglyceride values and a violation of the functional state of the liver with a cytolytic syndrome on the activity of AST and ALT and the total bilirubin, which may contribute to the progression of liver damage.

\section{References}

Anstee Q.M., Reeves H.L., Kotsiliti E., Govaere O., Heikenwalder M. (2019). From NASH to HCC: current concepts and future challenges. Nature Reviews Gastroenterology\&Hepatology, 16 (7), 411-428. doi: 10.1038/s41575-019-0145-7.

Bochar O.M., Sklyarova H.Y., Abrahamovych K.Y., Hromnats'ka N.M., Bochar V.T., Sklyarov E.Y. (2021). Metabolic syndrome, overweight, hyperleptinemia in children and adults. Wiadomości Lekarskie, 2, 313-316. DOI:10.36740/WLek202102126

Chalasani N., Younossi Z., Lavine J.E., Diehl A.M., Brunt E.M., Cusi K., Charlton M., Sanyal A.J. (2014). The "New Deadly Quartet» for cardiovascular disease in the 21st century: obesity, metabolic syndrome, inflammation and climate change: how does statin therapy fit into this equation? Current atherosclerosis reports abbreviation, 16 (1), 380. doi: 10.1007/ s11883-013-0380-2.

Diehl A.M., Day C. (2017). Cause, Pathogenesis, and Treatment of Nonalcoholic Steatohepatitis. The New England Journal of Medicine, 377, 2063-72. doi: 10.1056/NEJMra1503519

Fargion S., Porzio M., Fracanzani A.L. (2014). Nonalcoholic fatty liver disease and vascular disease: state-of-the-art. World Journal of Gastroenterology, 20 (37),13306-24. doi: 10.3748/ wjg.v20.i37.13306

Festuccia W.T. (2017). Turning up the heat against metabolic syndrome and non-alcoholic fatty liver disease. Clinical science (London), 131 (4), 327-328. doi: 10.1042/CS20160855.

Katsimardou A., Imprialos K., Stavropoulos K., Sachinidis A., Doumas M., Athyros V. (2020). Hypertension in Metabolic Syndrome: Novel Insights. Current Hypertension Reviews, 16 (1), 12-18. DOI: 10.2174/1573402115666190415161813

O'Neil A., Scovelle A.J., Milner A.J., Kavanagh A. (2018). Gender/Sex as a Social Determinant of Cardiovascular Risk. Circulation, 137(8), 854-864. doi: 10.1161/CIRCULATIONAHA.117.028595.

Schwabe R.F., Tabas I., Pajvani U.B. (2020). Mechanisms of Fibrosis Development in Nonalcoholic Steatohepatitis. Gastroenterology, 158 (7), 1913-1928. doi: 10.1053/j.gastro.2019.11.311. Targher G., Byrne C.D., Lonardo A., Zoppini G., Barbui C. (2016). Non-alcoholic fatty liver disease and risk of incident cardiovascular disease: A meta-analysis. Journal of Hepatology, 65 (3), 589-600. doi: 10.1016/j.jhep.2016.05.013. 
Vakalyuk I.I., Virstyuk N.G., Kazmiruk V.M. (2016) Progresuvannya fibrozu pechinky u xvoryh na stabil'nu ishemichnu xvorobu sercya na tli nealkogol'noyi zhyrovoyi xvoroby pechinky [Progression of liver fibrosis in patients with stable coronary heart disease combined with non-alcoholic fatty liver disease (2016)]. Gastroenterologyja - Gastroenterology, 4, 27-31. DOI: https://doi.org/10.22141/2308-2097.4.62.2016.81088

VanWagner L.B., Khan S.S., Ning H. et al. (2017). Body mass index trajectories in young adulthood predict non-alcoholic fatty liver disease in middleage: The CARDIA cohortstudy. Liver International, 38(4), 706-714. doi: 10.1111/liv.13603.

Zhou Y.J., Zhou Y.F., Zheng J.N., Liu W.Y., Van Poucke S., Zou T.T., Zhang D.C., Shen S., Shi K.Q., Wang X.D., Zheng M.H. (2017). NAFL screening score: A basic score identifying ultrasound-diagnosed non-alcoholic fatty liver. Clinica Chimica Acta, 475, 44-50. doi: 10.1016/j.cca.2017.09.020. 